\title{
Reflexóes Sobre a Trindade como Expressão do Amor em Nicolau de Cusa
}

\author{
Maria Simone Marinho Nogueira ${ }^{1}$
}

RESUMO: Procuramos, neste artigo, apresentar a reflexão de Nicolau de Cusa sobre a Trindade, em dois dos seus textos: De coniecturis e De visione dei. Nesses dois livros, a Trindade recebe uma série de outras designaçóes diferentes daquelas que aparecem nas citaçôes bíblicas ou, como ele próprio afirma, diferentes das usadas pelos nossos doutores. Nesse sentido, objetivamos mostrar, também, que as expressóes da Trindade podem ser lidas como expressóes do amor no pensamento do filósofo alemão.

PALAVRAS-CHAVE: Trindade. Amor. Nicolau de Cusa.

\section{INTRODUÇÃo}

A Trindade, nos textos de Nicolau de Cusa, recebe uma série de designaçôes diferentes daquelas que aparecem nas citaçóes bíblicas ou, como escreve o próprio Nicolau, diferentes das usadas pelos nossos doutores ${ }^{2}$. Em De visione dei, particularmente, os termos utilizados são: amor amans, amor amabilis e nexus amoris amantis e amabilis e, assim, nesse texto, o tema da Trindade é apresentado através da temática do amor. Entretanto, se, por um lado, o cardeal alemão emprega o amor para interpretar aquele dogma ${ }^{3}$, por outro lado, usa a própria Trindade para expressar a importância do amor. Dessa forma, se o amor pode ser compreendido como uma expressão da Trindade,

\footnotetext{
${ }^{1}$ Doutora em Filosofia pela Universidade de Coimbra. Professora do Departamento de Filosofia e Ciências Sociais e da Pós-Graduação em Filosofia (Mestrado) da Universidade Estadual da Paraíba. Líder do Principium - Núcleo de Estudo e Pesquisa em Filosofia Medieval: sites.uepb.edu.br/ principium. E-mail: mar.simonem@gmail.com

${ }^{2}$ Como, por exemplo: Unitas, Aequalitas e Conexio; Intelligens, Intelligibilis e Intelligere; Contrahens, Contrahibilis e Nexus.

${ }^{3}$ Apesar de utilizarmos o termo "dogma", não nos parece que Nicolau de Cusa se limite a uma exposição teológica. Pelo contrário, ele se esforça para apresentar o tema sob um ponto de vista filosófico. Sobre esse aspecto, veja-se FLASCH, 2003, p. 155.
} 
esta, por sua vez, também pode ser entendida como uma expressão do amor, e é isto o que pretendemos mostrar neste artigo, utilizando, para tanto, dois textos em específico: De coniecturis e De visione dei.

\section{A Trindade em De coniecturis: lumen intelligentiae, lumen iUstitiaE,} LUMEN AMORIS

Se, em De docta ignorantia, livro a ser sempre retomado, quando se trata de explorar a filosofia cusana, ${ }^{4}$ a "terceira" pessoa da Trindade ainda não aparece de forma táo explícita como sendo o amor ${ }^{5}$, não ocorre o mesmo com o livro que lhe é imediatamente posterior, o De coniecturis. Embora não dedique tantos capítulos especialmente à Trindade e, não obstante, use o mesmo esquema conceitual do De docta ignorantia para designar a Trindade (unitas, aequalitas e conexio), o De coniecturis começa por imprimir àquele esquema um certo dinamismo, sobretudo pela forma como exprime a conexio, estabelecendo, a partir daí, sua importância. Mesmo fazendo referências à Trindade, nos capítulos da primeira parte e, igualmente, em alguns capítulos da segunda parte daquele livro, é somente no seu último capítulo, o XVII, sugestivamente intitulado De sui cognitione, que repensa o homem, trinitariamente, em termos de unitas, aequalitas e conexio. Por isso, é sobre ele que faremos a nossa análise.

Nicolau de Cusa abre o capítulo dirigindo-se ao Padre Juliano ${ }^{6}$ e afirma que é próprio do homem ser um ser único, cuja humanidade participa da unidade na alteridade. Explica, depois, que Juliano pode notar que ele (Nicolau) é um homem e é diferente de Juliano e diferente de cada indivíduo. No entanto, é preciso esclarecer que, se a humanidade é contraível individualmente na alteridade, esta, por sua vez, é alteridade de uma unidade mais absoluta do que aquela que se encontra em nós próprios. $\mathrm{O}$ bispo de Brixen conclui essa parte, da qual deriva todo o resto do capítulo, asseverando: "Portanto, percebes que a primeira unidade ou entidade absolutíssima é completamente incontraível, a qual é participada incontraivelmente na variada

\footnotetext{
${ }^{4}$ Não só por ser um texto fundador, mas também porque nele estão contidos quase todos os temas que serão desenvolvidos nas obras posteriores.

${ }^{5}$ Embora, dentre as várias designaçôes, apareça na terceira pessoa da Trindade as expressóes "Spiritus Sanctus sive Amor" ou "Nexus sive Spiritus Amoris".

${ }^{6}$ Trata-se do cardeal Juliano Cesarini, a quem dedica o De coniecturis e a quem já havia dedicado o De docta ignorantia.
} 
alteridade" (NICOLAU DE CUSA, 1972, p. 173)7. Observemos que, nessa curta apresentação que fizemos das palavras iniciais, contidas no Cap. XVII do livro em questão, já nos são apresentadas as ideias de unidade, alteridade e humanidade em um contexto em que se evidencia não apenas uma estrutura trinitária, mas igualmente um esquema conceitual extremamente dinâmico, posto que aquela estrutura é exposta a partir do homem e do conhecimento que este pode ter de si mesmo, e não da própria Trindade como acontece, por exemplo, em De docta ignorantia.

Nessa obra, Nicolau de Cusa procura apresentar a Trindade a partir dela mesma, empregando para isso os conceitos de máximo, uno, eterno e trino. Por mais que use outras imagens - como, por exemplo, a matemática e os seus signos, o universo e a sua constituição, o homem e o seu intelecto -, todas elas, quando são usadas na sua relaçáo com a Trindade procuram explicitá-la e explicá-la. Em De coniecturis, por sua vez, o tema da Trindade já está estabelecido e, por isso, ainda que torne a aparecer ao longo do livro, não há necessidade de instituí-lo, porque isso já foi feito em De docta ignorantia. Todavia, a temática volta a ser referenciada, com ênfase, no último capítulo do De coniecturis (como já frisamos), mas não se trata do conhecimento da Trindade em si, mas do reconhecimento daquela no homem, o que significa, em última instância, a ratificação do homem como ser uni-trino e, desse modo, por meio do homem é mais fácil perceber a alteridade na unidade. Mesmo assim, Nicolau de Cusa mantém a mesma ideia que já estava em $D e$ docta ignorantia, qual seja, de que a precisão daquela verdade (da Trindade) é inatingível. Por conseguinte, no início do De coniecturis, enfatiza, fazendo referência ao De docta ignorantia, que a precisão da verdade é inatingível e, por isso, devemos concluir que toda proposição afirmativa que podemos formular acerca do verdadeiro é uma conjectura, pois não existe nenhuma proporção entre a nossa ciência (humana) e a ciência máxima. Portanto: "A unidade da verdade inatingível é conhecida pela alteridade conjectural e pela própria conjectura da alteridade na unidade simplicíssima da verdade" (NICOLAU DE CUSA, 1972, p. 4$)^{8}$.

\footnotetext{
7 "Absolutissimam igitur atque penitus incontrahibilem primam concipis unitatem seu entitatem, quae in alteritate varia incontrahibiliter participatur". De coniecturis, h III, Pars secunda, Cap. XVII, 172: 1-3. A tradução dos passos citados dos textos de Nicolau de Cusa, com exceção do De visione dei, é de nossa responsabilidade.

8 "Cognoscitur igitur inattingibilis veritatis unitas alteritate coniecturali atque ipsa alteritatis coniectura in simplicissima veritatis unitate. Clarius post haec huius notitiam intuebimur”. De coniecturis, h III, Pars prima, Prologus, 2: 9-12.
} 
Posto isso, retornemos ao homem e ao seu conhecimento. Como não poderia deixar de ser, o nosso filósofo recorre a um exemplo para explicar a Juliano a estrutura trinitária do homem e, ao mesmo tempo, volta a tratar da Trindade em termos de unidade, igualdade e conexão. Essa estrutura é também demonstrada no Idiota de mente, no capítulo XI, cujo título já resume bem a ideia da mente humana como imitação da divina, bem como sua estrutura trinitária: Quomodo omnia in deo sunt in trinitate, similiter et in mente nostra; et quomodo mens nostra est ex comprehendendi modis composita. Em um dado passo desse capítulo, ressalta:

Com efeito, a nossa própria mente, que é imagem da [mente] divina, deve ser considerada uma força superior, na qual o poder ser assimilada, o poder assimilar e o nexo de ambos são, em essência, uma só e mesma [coisa]. Daí, nossa mente náo pode compreender o que quer que seja, do mesmo modo que a mente divina, a não ser que seja una na trindade. (NICOLAU DE CUSA, 1983, p. 186-187) $)^{9}$.

Em De coniecturis, já é feita uma argumentação semelhante, mas o exemplo gira em torno da luz, da cor, da participação, do intelecto, da razão e dos sentidos. Não é uma demonstração difícil de ser compreendida, mas, como possui muitas divisóes, talvez seja mais fácil apresentá-la da maneira que segue ${ }^{10}$ :

\footnotetext{
9 "Est enim ipsa mens nostra, ut est similitudo divinae, uti vis alta consideranda, in qua posse assimilari et posse asssimilare et nexus utriusque in essentia unum sunt et idem. Unde non potest mens nostra, nisi sit una in trinitate, quicquam intelligere, quemadmodum nec mens divina". Idiota de mente, h V, Cap. XI, 133: 2-7.

${ }^{10}$ Nossa intenção, ao fazer o diagrama, não é apresentar a argumentação cusana no sentido de dar conta do movimento que ali se manifesta. Tampouco queremos substituir com o nosso diagrama a figura que aparece no Cap. XIV da parte primeira do De coniecturis, e que Nicolau de Cusa nomeou Circulus universorum. Queremos tão somente apontar as subdivisóes que o cardeal alemão faz no Cap. XVII da segunda parte do seu livro, de forma a evidenciar o carácter trinitário daquelas divisóes. Desse modo, nosso diagrama procura mostrar as divisões que aparecem nos $\$ \$ 172$ a 176 da referida obra.
} 


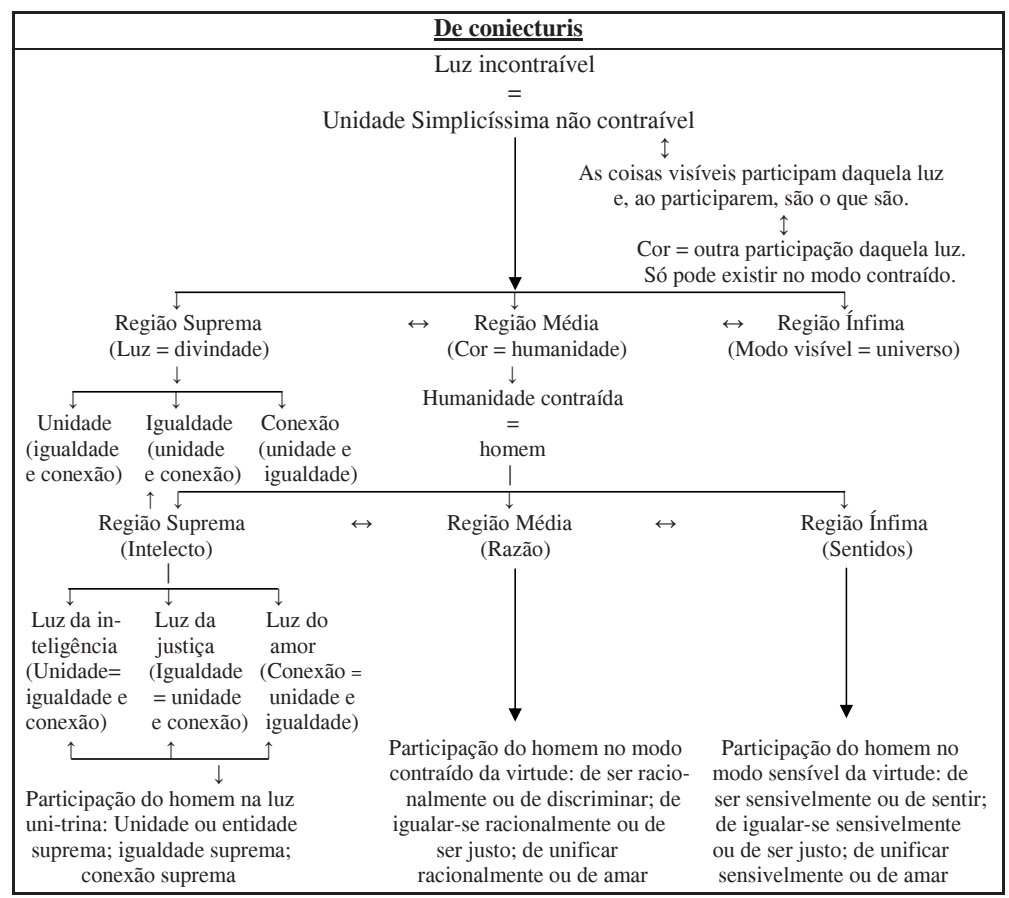

DIAGRAMA 1

Observemos que a Unidade simplicíssima não contraível, ou seja, Deus, é apresentada através da metáfora da luz. Luz que ilumina não apenas o mundo visível, mas também faz com que todas as coisas sejam o que são. Aquela Unidade encontra-se numa espécie de região suprema (só podendo ser alcançada pela humanidade contraída através da participação) e é, simultaneamente, tri-una ou uni-trina, posto que é composta pela unitas, pela aequalitas e pela conexio. Por sua vez, essas três instâncias, se assim podemos chamá-las, inter-relacionam-se, já que há igualdade e conexão na unidade, unidade e conexão na igualdade e, por fim, unidade e igualdade na conexão. Ora, nada de novo é expresso aqui em relação ao que foi exposto em De docta ignorantia, por isso, interessa-nos mais de perto observar o que acontece na região média onde está a humanidade contraída, ou seja, o próprio homem. Este, como podemos depreender do diagrama acima, é composto por três regióes, a exemplo das três primeiras regióes que aparecem no mesmo 
diagrama. Não obstante, não se trata mais de uma simples tripartição, como aquela que aparece em De docta ignorantia, no que dizia respeito à unidade do intelecto em Intelligens, Intelligibilis e Intelligere; mas uma tripartição que inclui o intelecto, a razão e os sentidos, fazendo derivar de cada uma dessas instâncias uma outra tripartição, de modo que cada uma delas participe, à sua maneira e na sua alteridade, da Unidade divina. Como bem escreve Beierwaltes (1977, p. 26), a esse propósito:

[...] - Especialmente o homem tem uma estrutura trinitária, que se lhe torna consciente como a unidade a realizar de razáo, justiça e amor na reflexão sobre si mesmo. Com isso, a autorreflexão ou o autoconhecimento do homem torna-se o ponto de partida para a experiência de uma "analogia trinitatis" no âmbito da finitude $[\ldots]^{11}$.

O que o nosso diagrama náo mostra, mas se encontra no texto, exatamente na transição ou na transposição das regiôes em geral (divindade, humanidade e universo) para as regióes que compóem o homem, é o apelo que Nicolau de Cusa faz a Juliano para que este procure descobrir a si mesmo na configuração que está sendo apresentada, de sorte a ponderar se ele aparece na suprema, na média ou na ínfima região. Ora, o que o filósofo de Cusa propóe é um mergulho do homem na sua própria humanidade e, a partir disso, a descoberta do seu nível de participação em relação à divindade infinita. Dessa forma, se Juliano, que aqui representa todos os homens, consegue ver-se, através do conhecimento de si e das suas açóes, mais próximo da regiáo suprema do que da regiáo ínfima, também saberá que participa, ampla e profundamente, da divindade na sua contração humana.

Todavia, aquela participação não é definitiva nem acabada, pois a conjectura que podemos formular daquela verdade será sempre uma conjectura, porém, por isso mesmo, ela poderá igualmente ser reformulada, e essa reformulação não significa somente uma "correção" no nível das ideias, mas principalmente um repensar sobre nós mesmos, sobre as nossas relaçóes com os outros, com o sagrado e com a própria vida. Ademais, repensar o lugar que ocupamos em termos trinitários dá um tal dinamismo à própria ideia da Trindade que nos vemos impelidos, naturalmente, a refletir sobre a unidade e a alteridade, não apenas em relação à Trindade, mas, de igual modo, em relação à nossa humanidade. Quer dizer, se, por um lado, somos seres diferentes

${ }^{11}$ Um outro estudo em que se pode perceber bem a relaçấo entre unidade e multiplicidade e a questão da participação no texto em análise encontra-se em KOCH, 1964, p. 164-173. 
em relação a cada homem, por outro lado, somos o mesmo ser em relação a nós próprios. Por sua vez, essa "mesmidade", que nos funda e nos identifica enquanto seres únicos e irrepetíveis, envolve uma série de outras coisas que podem, conforme notamos em Nicolau de Cusa, ser compreendidas através de uma estrutura trinitária.

Essa estrutura, como já demonstramos, inclui o intelecto, a razão e os sentidos e, embora cada uma dessas instâncias participe, tripartidamente e à sua maneira, da luz da regiáo suprema, fiquemos somente com a instância que se encontra na região suprema da natureza contraída, ou seja, o intelecto, e reflitamos um pouco mais acerca da sua natureza trinitária. Diferentemente do que ocorre em De docta ignorantia, a unidade do intelecto não é mais definida em termos de inteligente, inteligivel e entender, contudo, como indica o nosso Diagrama 1, pelas designaçóes luz da inteligência (lumen intelligentiae), luz da justiça (lumen iustitiae) e luz do amor (lumen amoris). Dessa forma, o homem participa da luz uni-trina não somente por possuir a virtude de entender, mas, de igual modo, também por possuir a virtude de ser justo e a virtude de amar.

Naturalmente que, em De docta ignorantia, a capacidade intelectual não deixa de fora a capacidade de ser justo e de amar, todavia, isso só fica claro nas leituras dos sinais que aparecem ao longo da obra. No livro que ora analisamos, De coniecturis, a justiça e, sobretudo, o amor aparecem de forma explícita, não sendo possível pensar no intelecto ou na sua importância sem pensar, igualmente, na justiça e no amor. Em decorrência, é afirmado que o intelecto "[...] é a virtude de compreender e a virtude de unir ou de amar que procede do intelecto e da sua intelecção, pois o intelecto ama o seu entender. $\mathrm{Na}$ verdade, o amor intelectual supóe o intelecto e aquele que entende" (NICOLAU DE CUSA, 1972, p.177) ${ }^{12}$.

Ao nomear o amor, na passagem acima, por amor intellectualis, Nicolau de Cusa estreita as relaçóes entre amar e entender, ao ponto de o ato de amar fazer parte da regiáo suprema do homem, o que não fica tão evidente no diagrama que apresentamos, porém, se torna claro no seguinte passo do livro em epígrafe: "Portanto, o intelecto é inclinado a compreender e a amar, a fim de que a natureza daquele seja aperfeiçoada, do mesmo modo que a razão [é inclinada] a raciocinar e os sentidos a sentir" (NICOLAU DE CUSA,

12 “[...] est intelligendi virtus, atque virtus conectendi amandive, quae ex intellectu eiusque intellectione procedit; amat enim intellectus intelligere suum. Intellectualis enim amor intellectum et ipsum intelligentem supponit”. De coniecturis, h III, Pars secunda, Cap. XVII, 176: 18-21. 
1972, p. 178 $)^{13}$. Depois disso, o místico alemão explica a Juliano como este existe à similitude de Deus. Tal como a unidade, a igualdade e a conexão mantêm uma unidade de sentido e de existência através das suas inter-relações, assim o homem, como a Trindade, une as suas três regiôes numa relação de complementaridade, mas tendendo sempre para a sua região suprema, na busca da unidade da luz da inteligência, da justiça e do amor. Assim, realizase na unidade por sua virtude intelectiva, na igualdade por sua virtude de ser justo e na conexáo por sua virtude de amar. É interessante o modo gradual com que apresenta a concepção de humanidade, através dos termos unitas, aequalitas e conexio, asseverando que a humanidade contraída em Juliano é uni-trina, e a unidade ou a entidade individualmente contraída é na igualdade e na conexão. De tal modo, Juliano existe como homem através da entidade da humanidade, na qual há igualdade, justiça ou ordem e conexão ou amor ${ }^{14}$. Conclui essa argumentação com as seguintes palavras:

E, como na própria unidade está aquela ordem da justiça, do mesmo modo, na unidade [está] uma certa conexão amorosa. Na verdade, a conexão está na própria entidade para que todas as coisas sejam um único homem. Pois, depois que a própria conexão deixa de existir na unidade, de forma semelhante, será forçoso faltar o teu ser próprio humano na sua unidade. (NICOLAU DE CUSA, 1972, p.180) ${ }^{15}$.

Notemos que, apesar da gradação com a qual Nicolau de Cusa apresenta a unidade de todas as coisas no homem, ele termina por evidenciar que, malgrado haja uma gradação, o mais importante para que esta se mantenha numa unidade de sentido - onde as diferenças ou a pluralidade das coisas não se percam numa alteridade sem referência à unidade - é que não lhe falte a conexão na unidade, quer dizer, que não lhe falte o amor. Beierwaltes (1977, p. 27-28) compreende a referência da Trindade à unidade como

\footnotetext{
13 "Inclinatur igitur intellectus ad intelligere et amare, ut perficiatur natura eius, ita ratio ad ratiocinari, sensus ad sentire". Idem, ibidem, 177: 11-12.

${ }^{14}$ Nicolau de Cusa acrescenta que tudo o que existe no homem é ordenado, de forma justa, na própria unidade. E assim os membros do corpo são ordenados em relaçấo ao corpo, este em relação à alma vital, esta em relação à sensível, esta em relação à racional, esta em relaçáo à intelectual e assim sucessivamente.

15 "Et quomodo in ipsa unitate est iustitialis ille ordo, ita quidem et conexio amorosa in unitate. Conexio enim in ipsa entitate est, ut omnia sint unus homo. Postquam enim conexio ipsa in unitate esse desinit, unum tuum humanum esse similiter deficere necesse erit". De coniecturis, h III, Pars secunda, Cap. XVII, 179: 11-15. Volta a afirmar, em De possest, a importância da conexão para a existência de todas as coisas, entretanto, usa o termo nexus, cf. Trialogus de possest, h XI 2 , $\$ \$ 47$ e 51.
} 
regresso pensante do uno a si mesmo, regresso que é amor ou conexão e que se realiza enquanto autoidentidade relacional e reflexiva. Ora, para que todas as coisas estejam em um só homem, fazendo deste um ser único e irrepetível, é necessário que a conexão esteja na própria entidade e, assim, como mostra o passo referenciado no fim do parágrafo anterior, se deixar de existir a conexão na unidade, igualmente deixará de existir o próprio ser humano. Aqui reside a importância da explicitação da palavra conexio, pois o nosso místico não escreve "se deixar de existir o inteligir ou o intelecto na unidade...", mas "se deixar de existir a conexão na unidade..." 16 . O que nos faz lembrar mais da importância do amor do que da relevância do intelecto para a assimilação ao divino, no sentido mesmo do Hino à Caridade de Sáo Paulo e que o nosso filósofo retoma e reitera, ao longo dos seus escritos. De tal forma, ele pode acrescentar que Deus é a conexáo infinita ou o infinito amor absoluto e, por isso, todo o amor com o qual amamos é sempre menor do que o amor com o qual ele pode ser amado; mesmo assim, quanto mais o amamos, mais participamos da sua divindade.

Ele chega a asseverar que aquela conexão de amor é a mais duradoura e que dizer amor significa dizer conexão ou unidade. Por outro lado, esse amor, que une tanto o amante ao amável quanto a cabeça ao corpo, procede da unidade e da igualdade ${ }^{17}$. Nesse sentido, mostra, novamente, a necessidade de pensar aquelas três categorias (unitas, aequalitas e conexio) como uma unidade que faz de cada indivíduo um ser único e irrepetível. Juliano e, portanto, cada um dos homens deve procurar o seu lugar naquela unidade trina, repensando a sua maneira de agir enquanto ser intelectivo, justo e amante. Entretanto, nesse repensar, Nicolau de Cusa dá, mais uma vez, um especial destaque ao amor e por isso afirma, chamando novamente a atenção de Juliano: "Além disso, sabes isto: amar Deus é ser amado por este, porque Deus é caridade" (NICOLAU DE CUSA, 1972, p.182) ${ }^{18}$. Participar desse amor é participar da Trindade divina e, assim, quanto mais amamos, mais participamos. Além disso, do fato de Deus ser amor verdadeiro, absoluto e infinito, nada de grave poderá acontecer àquele que ama, bem como, lembrando mais uma vez o Hino à

\footnotetext{
${ }^{16}$ Colocadas as coisas nesses termos, nâo é do intelecto enquanto capaz de entender que nos lembramos, mas do homem enquanto capaz de amar, embora essa capacidade pertença à instância intelectual.

${ }^{17}$ Com isso, retoma não apenas a designação da Trindade usada em De docta ignorantia (unitas, aequalitas e conexio), como também antecipa a nova nomeaçáo que será usada em De visione dei (amor amans, amor amabilis e nexus de ambos).

18 "Cognoscis etiam hoc esse deum amare quod est amari a deo, cum deus sit caritas". De coniecturis, h III, Pars secunda, Cap. XVII, 182: 6-7.
} 
Caridade de São Paulo, tudo pode ser suportado, se amarmos verdadeiramente a Deus na igualdade da unidade de ser e de amar. Ao menos é com essa ideia que encerra o De coniecturis:

Nada de grave ou de adverso poderá acontecer a ti, se compreendes e aceitas que tudo aquilo, que parece contrário aos sentidos, deve ser suportado na igualdade do ser e do amar, porque isto é participar de forma feliz e nobre da divindade. Vês, também, naquela própria igualdade, já referenciada, ser complicada toda virtude moral que não pode ser virtude a não ser que exista na participação daquela igualdade. (NICOLAU DE CUSA, 1972, p.182) ${ }^{19}$.

Verificamos, por conseguinte, que as palavras unitas, aequalitas e conexio tornam a ser usadas em De coniecturis, mas são revestidas de uma outra iluminação da qual derivam a luz da inteligência, a luz da justiça e a luz do amor. Com isso, Nicolau de Cusa procura explicitar a ideia da Trindade, utilizando as próprias virtudes humanas, dando a entender que assim como a Trindade, o homem realiza a sua plena unidade humana (como a Trindade realiza a sua plena unidade divina) na conexão da inteligência, da justiça e do amor. Como Deus é purus intellectus, purus bonus e purus affectus, procurar imitá-lo nas açóes de ser inteligente, ser justo e ser amante significa procurar participar da divindade do modo que é possível ao homem, pressupondo um constante aperfeiçoamento dele próprio. De tal forma, a unitas, a aequalitas e a conexio, revestidas ou pensadas a partir das virtudes humanas, ganham outros contornos e dão um certo dinamismo ao mesmo esquema conceitual do De docta ignorantia ${ }^{20}$. Para

\footnotetext{
19 "Nihil tibi grave adversumve evenire poterit, si id omne, quod sensibus adversum videtur, intelligis atque ita amplexaris in aequalitate unitatis essendi atque amandi ferendum, cum hoc sit divinitatem nobiliter feliciterque participare. Vides autem in ea ipsa aequalitate iam dicta omnem moralem complicari virtutem nec virtutem esse posse, nisi in huius aequalitatis participatione exsistat". Idem, 183: 9-15. Na verdade, essas palavras não encerram o De coniecturis, malgrado possamos destacar que encerram a argumentação cusana. Há ainda o parágrafo 184, no qual Nicolau de Cusa faz somente breves consideraçôes sobre a sua intenção ao escrever o livro, embora seja interessante notar que o texto se encerra com a unidade do amor.

${ }^{20}$ Não quer isso dizer que já não haja um certo dinamismo no esquema conceitual do De docta ignorantia, sobretudo no livro III, onde é abordada a ideia da encarnação descrita sob os moldes da Trindade. Assim explicita André, logo depois de refletir sobre as relaçōes entre Pai, Filho e Espírito Santo, naquele contexto: "Todavia, ao afirmar-se, assim, a concretização da plenitude da mediação na figura de Jesus, este constitui-se em modelo do homem como tarefa, acentuando ainda mais todo o dinamismo inerente a esta antropologia: se o Verbo, enquanto Filho, é a igualdade (na trindade da unidade, da igualdade e da conexão), o homem é tendência para a igualdade, e se a filiaçấo divina, realizada em Cristo, é igualdade da identidade, a filiação a realizar pelo homem é semelhança dessa igualdade. E se a primeira é uma filiação natural e absoluta, a segunda é aquilo a que Nicolau de Cusa chama uma "filiação por adopção". Tal filiação por adopção é entendida também ela como um
} 
concluir essa parte, podemos enfatizar que, apesar das muitas divisóes que acompanhamos, ao longo do Cap. XVII do De coniecturis, o terceiro elemento da estrutura trinitária mantém-se como amor e com o sentido fundamental de algo que une e, portanto, que reconduz todas as coisas à unidade.

\section{A Trindade em DE VISIONE DEI: AMOR AMANS, AMOR AMABILIS E NEXUS AMORIS}

Em De docta ignorantia, a Trindade é pensada em termos de unitas, aequalitas e conexio; em De coniecturis, aquelas designaçôes são "complementadas" pelas expressóes lumen intellectualis, lumen iustitiae e lumen amoris; em De visione dei, por sua vez, Nicolau de Cusa adota as expressóes amor amans, amor amabilis e nexus amoris amantis et amoris amabilis ${ }^{21}$. Dessa forma, o que podemos perceber, gradativamente, é que o nosso filósofo apresenta o dogma da Trindade através da temática do amor e, assim, como ápice dessa gradação, gostaríamos de nos concentrar, agora, no De visione dei. Apesar da riqueza de temas que pode ser extraída desse livro, podemos dizer que todos os temas derivam da metáfora do olhar que é, simultaneamente, uma metáfora do amor. Com a temática da Trindade acontece a mesma coisa, ou seja, assim como Deus é visível, é visto e é nexo de ambos, é também amante, amável e nexo de amor amante e de amor amável. Logo, a interpretaçấo da Trindade exposta em De visione dei, de igual modo, está fundada na identificação de ver e amar. Vejamos, então, como Nicolau de Cusa refere-se à Trindade em De visione dei.

Diferentemente do que ocorre em De docta ignorantia e de maneira semelhante ao que acontece no De coniecturis, o De visione dei não dedica,

processo, o processo da deificatio ou da deiformitas, que inscreve uma dimensão escatológica como configuradora de toda esta antropologia e que se prende com a concepção do homem como imago viva, ou símbolo vivo, dotado da capacidade de se tornar cada vez mais semelhante àquele de quem é imagem, tomando como modelo (ou seja, como "caminho", como "verdade" e como "vida") Cristo, mediador universal”. ANDRÉ, 2003, p. XXXV-XXXVI.

${ }^{21}$ Conforme podemos ler no aparato crítico da edição do De visione dei, os três termos provêm de Agostinho e de Raimundo Lúlio, sendo essa ideia confirmada por Haubst e Colomer (cf. h VI, 2000, $\$ \$ 71,72$ e 81). No entanto, esclarece-nos Romano, num texto muito didático sobre a influência de Raimundo Lúlio na Trindade do De icona em Nicolau de Cusa, que Haubst, depois de reclamar, em primeiro lugar, como fonte daquelas designaçôes o De trinitate de Agostinho, percebe que "[...] l'argomento agostinano qui richiamato si conclude nella dualità dell'atto di conoscere e amare e del soggetto amante e amato. Haubst conclude da ciò che per superare la dualità è necessario supporre in Cusano l'eredità delle letture lulliane". Dando prosseguimento ao texto, afirma, depois de introduzir as ideias de Colomer, em que este reconhece a influência de Agostinho no passo reportado por Haubst, mas observa que "[...] in Agostino manca il termine 'amabilis': la fonte letterale deve derivare allora dalla teoria dei correlativi di Lullo, che dà la compiuta forma triadica alle dinamiche dell'amore descritte da Agostino". ROMANO, 2005, p. 159-160 respectivamente e p. 155-174. 
expressamente, muitos capítulos ao tema da Trindade e, por isso, restringirnos-emos aos capítulos XVII e XVIII. O primeiro coloca o princípio unitrino como necessário para a perfeição divina, o segundo aborda a questão da felicidade que não poderia existir, se Deus não fosse trino. Retomam-se, portanto, as relaçóes entre a identidade e a diferença na sequência da exposição sobre a liberdade e, com esta, do conhecimento de si que nos faz lembrar a abordagem feita em De coniecturis. Todavia, se neste livro somente o "terceiro" elemento da Trindade era designado por amor, em De visione dei os "três" elementos assim são nomeados.

O Cap. XVII, intitulado Quod deus non nisi unitrinus videri perfecte potest, é orientado por três ideias: Deus como amor perfeito e natural, o muro do Paraíso como limite do intelecto e a reflexão sobre a Trindade, a partir do próprio homem. Como o título do capítulo já indica, a perfeição do amor divino provém da sua Trindade, incluindo ali a sua infinitude ${ }^{22}$ e a sua unidade. Não é ao acaso, pois, que Nicolau de Cusa, ao pensar a Trindade nessa parte do seu texto, trabalhe não só com a ideia do amor amante, do amor amável e do nexo de ambos, mas acrescente ao fato de Deus ser amor a noção de infinito e de unidade. Assim o expressa: "Efetivamente, a tua amabilidade, que é o poder ser infinitamente amado, deve-se ao fato de ser simultaneamente o poder amar infinitamente. Do poder amar infinitamente e do poder ser infinitamente amado provém o nexo infinito do amor entre o amante infinito e o infinito amável”, ou, ainda, "[...] e isto não é senão o que vejo na tua absoluta unidade, na qual vejo a unidade que une, a unidade unível e a uniáo de ambas" (NICOLAU DE CUSA, 2000 , p. 197-198 $)^{23}$. Nesse sentido, de o fato de Deus ser amor, entenda-se, amor infinito, provém o nexo entre o amante infinito e o infinito amável, logo, ele é o infinito amante, o infinito amável e o nexo. De igual maneira, como a ideia do amor enquanto conexão se mantém, independentemente do nome que receba a "terceira" pessoa da Trindade, Deus também é a unidade que une, a unidade unível e a união entre ambas.

Por conseguinte, o que podemos perceber, seja através da designação de amor, seja pelos termos infinito ou unidade, é que a perfeição de Deus é

\footnotetext{
${ }^{22}$ Os dois capítulos sobre a Trindade vêm imediatamente após os dois capítulos sobre o infinito.

23 "Amabilitas enim tua, quae est posse in infinitum amari, est, quia est posse in infinitum amare. A posse in infinitum amare et posse in infinitum amari oritur amoris nexus infinitus ipsius infiniti amantis et infiniti amabilis", ou ainda, "Et hoc non est aliud quam illud, quod video in absoluta unitate tua, in qua video unitatem unientem, unitatem unibilem et utriusque unionem". De visione dei, h VI, Cap. XVII, 71: 7-10 e 16-18, respectivamente. Em relação aos passos do De visione dei, estamos usando a tradução de ANDRÉ, 2000, com pequenas correções.
} 
apresentada como algo trino; no entanto, é preciso compreender, também, que aquela estrutura trinitária é simples, daí, como indica o título do Cap. XVII, Quod deus non nisi unitrinus videri perfecte potest. Essa ideia da unidade da trindade e da perfeição de Deus é repetida ao longo do referido capítulo, de diferentes formas, culminando na afirmação de que a essência de Deus é trina e de que essa essência não seria tão natural e tão perfeita, se assim não o fosse. Obviamente que é necessário salvaguardar a unidade divina $\mathrm{e}$, por isso, a trindade desta náo pode ser compreendida como sendo composta por três coisas ${ }^{24}$. Logo, devemos entendê-la como uma pluralidade que é unidade e uma unidade que é pluralidade, valendo, aqui, o princípio da supertranscendência divina, o qual já encontramos em De docta ignorantia e que aparece em todos os textos cusanos ${ }^{25}$. Por tudo isso, pode o nosso filósofo asseverar: "Mas, quanto mais simples o amor tanto mais perfeito. Tu, porém, Deus meu, és o amor sumamente perfeito e simples. Por isso, tu és a própria essência perfeitíssima, simplíssissima e naturalíssima do amor" (NICOLAU DE CUSA, 2000, p. 1982)

É interessante notar que, ao aludir à simplicidade de Deus, Nicolau de Cusa continua a usar uma estrutura trina, ou seja, Deus é a própria essência perfeitíssima, simplicissima e naturalíssima do amor. Percebemos ainda aqui os ecos do grau superlativo empregado pelo pseudo-Dionísio, na sua Mystica theologia. Ora, o cardeal alemão está a preparar o leitor, mais uma vez, para a compreensão do que vai ser dito, pois isso ultrapassa todo o nosso intelecto. Por um lado, não é possível pensar a Trindade em termos meramente racionais, porque a distinção entre a unidade e a pluralidade não é uma distinção numérica, mas de essência: a unidade divina é essencialmente trina e não pode ser concebida de outra forma, porém, essa essência trina não pode igualmente ser concebida fora da ideia de unidade, uma vez que, assim, a unidade absoluta, que é o próprio Deus, se perderia na multiplicidade das coisas. Nesse sentido, não é pela distinção numérica que podemos alcançar o

\footnotetext{
${ }^{24} \mathrm{Em}$ De possest, torna a repetir a ideia da unidade da Trindade, chamando atenção, mais uma vez, para o fato de não se tratar de uma unidade matemática, mas de uma unidade verdadeira e viva que complica todas as coisas. Do mesmo modo, também não se trata de uma Trindade matemática, mas de uma Trindade de relaçóes entre si, na qual existe alegria e perfeição. De uma vida assim, una e trina, procede o espírito de amor e a alegria sempiterna. Cf. Trialogus de possest, $\mathrm{h} \mathrm{XI}_{2}, \$ \$ 49-50$.

${ }^{25}$ Para a relação unidade-pluralidade na filosofia cusana, remetemos ao já citado estudo de BEIERWALTES, 1977.

26 "Quanto autem amor simplicior, tanto perfectior. Tu autem, deus meus, es amor perfectissimus et simplissimus. Tu igitur es ipsa essentia perfectissima et simplicissima et naturalissima amoris”. De visione dei, h VI, Cap. XVII, 72: 10-12.
} 
sentido daquelas relaçóes, porque Deus, como salienta o místico moselano, não é nem o singular nem o plural do número, mas é o que está acima de toda a pluralidade e de toda singularidade, sendo, portanto, uni-trino e só podendo ser percebido de tal forma pela nossa capacidade intelectual que alcança o muro do Paraíso.

Náo é a primeira vez que Nicolau de Cusa usa a metáfora do muro do Paraíso, em De visione dei. Já o tinha feito em capítulos anteriores ao XVII e volta a fazê-lo nos capítulos XX e XXIII. Apesar dessa recorrência, não vamos explorar aqui todas as dimensóes que aquela metáfora comporta, mas gostaríamos de explicitá-la como limite do intelecto, ou seja, a imagem do muro significa não só um limite real, posto que todo muro demarca ou delimita um espaço, mas significa, também, um limite epistemológico, uma vez que, como afirma Nicolau de Cusa, aqueles que se aproximam de Deus se deparam com o muro que cerca o lugar em que ele habita na coincidência ${ }^{27}$. Deparar-se com o muro quer dizer, metaforicamente, encontrar o próprio limite do que pode o nosso conhecer. Por outro lado, se o muro demarca, dividindo assim o que pode ser visto aquém e além dele mesmo, ele igualmente determina o cruzamento de dois espaços diferentes, já que é definido como "[...] a coincidência em que o depois coincide com o antes, o fim coincide com o princípio, em que alfa e ômega são o mesmo" (NICOLAU DE CUSA, 2000, p. 171 ${ }^{28}$. Logo, o muro, aqui entendido como limite, não é apenas o que separa, mas igualmente o que une ${ }^{29}$.

Nesse sentido, e falando em termos cusanos, o muro é a disjunção e simultaneamente a conjunção, é tudo e ao mesmo tempo nada; porém, Deus está além do muro e, portanto, para lá da coincidência dos opostos e permanece desligado (absolutus) de tudo que pode ser dito ou ser pensado. Daí a razão só chegar até o muro, pois, se ela não consegue pensar a coincidência dos opostos, também não seria capaz de ver para além daquela. É preciso, pois, transpor o muro e perceber que em Deus o impossível é necessário e,

\footnotetext{
${ }^{27}$ Cf. De visione dei, h VI, Cap. X. Para a metáfora do muro do Paraíso enquanto uma "cartografia do conhecimento", remetemos ao texto de ANDRÉ, 2006. Para a mesma metáfora e a exploração dos seus múltiplos sentidos, também já referida por nós, HAUBST, 1989. Para a relação daquela com a Trindade, mais especificamente a III parte do artigo de Haubst, p. 183 e sq.

28 "[...] coincidentia illa, ubi posterius coincidit cum priore, ubi finis coincidit cum principio, ubi alpha et o sunt idem". De visione dei, h VI, Cap. X, 42: 8-9.

${ }^{29}$ Pelos títulos dos capítulos em que aparece a metáfora do muro, já podemos ter uma ideia da riqueza daquela imagem, bem como a certeza de que ela é ali posta a fim de que experimentemos, um pouco, a coincidência dos opostos.
} 
assim, afrontar o murus absurditatis. No capítulo em que ora nos detemos, esse afrontamento refere-se à uni-trindade ou à tri-unidade divina. No muro do Paraíso, o que o nosso intelecto "vê" é que a pluralidade coincide com a singularidade, e que aquela pluralidade é sem número, porque numerar é alterar e na Trindade não há alteraçáo; por isso, a pluralidade que vemos em Deus é alteridade sem alteridade, isto é, é a própria identidade ${ }^{30}$. Posto isso, Nicolau de Cusa conclui sua incursão pela metáfora do muro, declarando:

O muro delimita, pois, a potência de todo o intelecto, ainda que os olhos observem mais além o Paraíso. Todavia, não podem dizer nem entender aquilo que veem. Trata-se, pois, do seu amor secreto e de um tesouro escondido que, ainda que encontrado, permanece escondido, pois se encontra dentro do muro da coincidência do escondido e do manifesto. (NICOLAU DE CUSA, 2000, p. 200) $)^{31}$.

O intelecto, assim, chega até à coincidência dos opostos conseguindo captar o cruzamento do antes com o depois do muro, todavia, é aí o seu limite, ainda que os olhos observem o Paraíso. No muro da coincidência, é possível compreender, limitadamente, como Deus é trino e uno ao mesmo tempo, porém, seu amor ou a posse deste permanece secreta e escondida, podendo, no entanto, ser pré-saboreável na representação, porque o que pertence à essência do amor contraído náo pode faltar ao amor absoluto que comunica o seu ser a todas as coisas. Estabelecido isso, nosso filósofo procura agora compreender a Trindade a partir da sua representação no homem.

Desse modo, depois de mostrar a Trindade como amor perfeito e natural, exibindo também a experiência que dela podemos ter, ainda que limitada, através da metáfora do muro do Paraíso, Nicolau de Cusa, à maneira do que acontece em De coniecturis, transporta aquelas imagens para o próprio modelo humano à medida que este possui, contraidamente, o amor absoluto que é trino e uno. Por conseguinte, o homem reconhece-se como amante, amável e nexo, reconhecendo-se, ao mesmo tempo, como uno. Dessa maneira, como uma espécie de oração, diz:

\footnotetext{
${ }^{30}$ Para todos os passos da argumentação cusana, veja-se os $\$ \$ 74$ e 75 do Cap. XVIII do De visione dei, h VI, Cap. XVIII, $\$ \$ 74$ e 75.

31 "Claudit enim murus potentiam omnis intellectus, licet oculus ultra in paradisum respiciat, id autem, quod videt, nec dicere nec intelligere potest. Est enim amor secretus suus et thesaurus absconditus, qui inventus manet absconditus. Reperitur enim intra murum coincidentiae absconditi et manifesti”. De visione dei, h VI, Cap. XVII, 75: 9-14.
} 
Concedes-me, assim, Senhor, que em mim veja o amor, porque me vejo como o amante. E na medida em que vejo que me amo a mim próprio, vejo-me como amável. E vejo que sou o nexo assaz natural de ambos. Eu sou o amante, eu sou o amável, eu sou o nexo. Um só é o amor, sem o qual não pode haver nenhum três. Sou um só, eu que sou o amante, eu mesmo que sou amável, eu mesmo que sou o nexo que brota do amor com que me

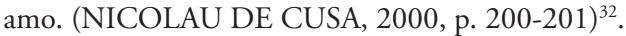

A forma como Nicolau de Cusa desenvolve a ideia da uni-trindade ou da tri-unidade, exposta no passo acima, reflete-se de maneira simples e extremamente profunda no conhecimento que o homem pode ter de si próprio. Logo, se admitimos que o nosso amor é a nossa essência, como o é em Deus, então na unidade da nossa essência haveria o amante, o amável e o nexo e, na trindade dessas três coisas, haveria a unidade da essência. Apesar disso, somos capazes de perceber que o amante, o amável e o nexo se distinguem um do outro, pois podemos amar alguém e não sermos amados por esse alguém, como, por exemplo, um filho que, por vezes, não cuida da mãe que com tanta ternura o ama.

Em vista disso, cada um de nós é o amante, o amável e o nexo, uma vez que o amor é de uma essência trinitária e não podemos amar a nós próprios, nem a Deus, nem aos outros sem amor; contudo, se em relação a cada ser essas três coisas são uma unidade, porque o amor é trino e não é possível amar sem amor, em relação ao outro, aquelas três coisas são distintas, pois ainda que amemos a ponto de estendermos o nosso amor amante ao ser amado, o nosso amor amante não arrasta conosco o nosso amor amável, logo, nem sempre nos tornamos amáveis para o ser amado. Em decorrência, Nicolau de Cusa procura mostrar a unidade da Trindade e a trindade da unidade através do amor que é, ao mesmo tempo, amante, amável e nexo. A despeito do seu esforço, o capítulo encerra-se com as seguintes palavras: "Mas sabes onde cheguei. Eu, porém, não sei e basta-me a tua graça com a qual me dás a certeza de que és incompreensível e me elevas à firme esperança de chegar ao gozo de ti, se te escolher como guia" (NICOLAU DE CUSA, 2000, p. 203) 33. A incerteza

32 "Tu enim sic das, domine, quod in me video amorem, quia video me amantem. Et quia video me amare me ipsum, video me amabilem, et naturalissimum nexum me esse video utriusque. Ego sum amans, ego sum amabilis, ego sum nexus. Unus est igitur amor, sine quo non posset aliquod trium esse. Ego unus sum, qui sum amans, et ille idem, qui sum amabilis, et ille idem, qui sum nexus exsurgens ex amore, quo me amo". De visione dei, h VI, Cap. XVII, 76: 4-10.

33 "Quo autem perveni, tu scis, ego autem nescio, et sufficit mihi gratia tua, qua me certum reddis te incomprehensibilem esse, et erigis in spem firmam, quod ad fruitionem tui te duce perveniam". De visione dei, h VI, Cap. XVII, 79: 11-14. 
quanto ao ponto de chegada demonstra, de alguma forma, tanto a ideia de que Deus somente é compreensível incompreensivelmente, quanto a ideia de que a sua compreensão só se realiza enquanto busca. Assim, depois de afirmar que Deus só poderia ser visto perfeitamente como uni-trino, intitula o outro capítulo dedicado à Trindade por Quod nisi deus trinus esset, non esset felicitas'.

Se a compreensão daquilo que nos ultrapassa se realiza enquanto busca, esta, por sua vez, concretiza-se através do amor divino que é trino e uno, posto que Deus, como amor amante não odeia ninguém, como amor amável ama tudo que é amável, e como nexo derrama o seu amor sobre todas as criaturas. No entanto, malgrado amar cada uma das suas criaturas e de estender o seu amor sobre todas elas, nem todas são capazes de amá-lo. Contudo, concentremo-nos no amor divino como meio para atingir a felicidade, uma vez que pergunta o místico alemão: "Mas, Deus meu, como é que pode atingir o seu fim a tua esposa, a alma humana, se tu não fosses amável de tal maneira que te amando, assim, amor amável, possa atingir o nexo e a união da suprema felicidade?" (NICOLAU DE CUSA, 2000, p. 205) ${ }^{34}$. Apesar do tom afetuoso com que dirige a pergunta, a resposta dada remete para a conjunção do intelecto e da vontade e, por isso, ele responde: "Na verdade [...] pode então o intelecto criado atingir em ti, Deus, seu inteligível, a uniâo contigo e a felicidade. E igualmente porque és o amor amável pode a vontade amante criada obter em ti, Deus, seu amável, a união e a felicidade" (NICOLAU DE CUSA, 2000, p. 205) ${ }^{35}$.

Notemos que o nosso filósofo, a exemplo do que já fizera em De docta ignorantia, torna a denominar a Trindade por intelecto inteligente, intelecto inteligível e nexo de ambos, o que permite ao intelecto criado (o homem) atingir em Deus (seu inteligível) a felicidade. Do mesmo modo, o fato de Deus ser o amor trino (amante, amável e nexo) faculta à vontade amante criada (o homem) obter em Deus (seu amável) a felicidade. Esta, nesse contexto, não é outra coisa senão a união com Deus e, mais uma vez, percebemos que o homem se une ao divino, imitando-o naquilo que ele tem de mais semelhante com Este, o intelecto e o afeto ou o inteligível e o amável. Assim, o homem só pode chegar à união com Deus, porque este, de forma semelhante, mas em grau absoluto, é amável e inteligível e, como podemos ler na sequência do

\footnotetext{
34 "Sed quomodo posset attingere finem suum sponsa tua, deus meus, anima humana, nisi tu fores diligibilis, ut sic te diligibilem diligendo ad nexum ac unionem felicissimam pertigere posset?". De visione dei, h VI, Cap. XVIII, 80: 21-24.

35 "Nam [...] intellectus creatus in te deo suo intelligibili unionem tui et felicitatem assequi potest. Sic cum sis amor amabilis, potest creata voluntas amans in te deo suo amabili unionem et felicitatem assequi”. De visione dei, h VI, Cap. XVIII, 81: 4-12.
} 
texto, o "objeto" do amante (homem) é o amável (Deus), do mesma maneira que o "objeto" do intelecto (homem) é o inteligível (Deus). Logo, na relação de amar e ser amado ou de compreender e de ser compreendido reside o nexo, que, na sua capacidade de unir fortemente o amante ao amável ou o intelecto ao inteligível, pode ser denominado filiação e é com referência a esta que Nicolau de Cusa termina esse capítulo:

[...] na verdade, não conhecemos nexo mais estreito que o da filiação. Se este nexo de uniáo é o máximo, pois maior não pode haver, então acontecerá necessariamente que, não podendo tu, Deus amável, ser mais amado pelo homem, tal nexo atinja a filiação mais perfeita, de tal maneira que essa filiação seja a perfeição que complica toda filiação possível, pela qual todos os filhos alcançam a última felicidade e a perfeição. Neste filho altíssimo está a filiação como a arte no mestre ou a luz no sol. Nos outros, em contrapartida, está como a arte nos discípulos ou a luz nas estrelas. (NICOLAU DE CUSA, 2000, p. 206) ${ }^{36}$.

\section{É interessante o fato de Nicolau de Cusa encerrar esse capítulo com} a ideia da filiação, já que esta representa o nexo mais estreito ou mais forte entre o homem e Deus. É certo que tal referência à filiação prepara o leitor para o tema do dogma da encarnação, que será desenvolvido nos capítulos que se seguem e, por isso, no fim do passo citado é comparada a filiação de Jesus Cristo, filho altíssimo, com a filiaçáo dos outros homens. Mesmo assim, é certo também que esse nexo de união, relativamente ao qual não pode haver maior, revela a importância do amor na sua relação com a Trindade, visto que o nexo é nexo de amor e somente por ele é possível atingir a união da suprema felicidade. Mais do que isso, o nexo une o amante ao amável de forma perfeita - já que não existe amor perfeito sem o amante, o amável e o nexo - por isso,

\footnotetext{
36 “[...] nexu enim filiationis non cognoscimus strictiorem. Quod si hic nexus unionis est maximus, quo maior esse nequit - hoc evenire necesse erit, quia tu, deus amabilis, plus diligi non potes ab homine - tunc nexus ille usque ad perfectissimam filiationem pervenit, ut filiatio illa sit perfectio complicans omnem possibilem filiationem, per quam omnes filii ultimam felicitatem et perfectionem assequuntur. In quo altissimo filio filiatio est ut ars in magistro aut lux in sole, in aliis vero ut ars in discipulis aut lux in stellis”. De visione dei, h VI, Cap. XVIII, 82: 4-12. Ao tema da filiaçăo divina, Nicolau de Cusa dedicou um dos seus escritos, De filiatione dei (1445). O mesmo tema é apresentado em De deo abscondito e em De quaerendo deum. A prova de que se trata de um tema importante no pensamento cusano é o fato de o mesmo ser retomado em escritos posteriores aos que referimos acima, como, por exemplo, o De visione dei e o De pace fidei, além de ser repetido ao longo dos seus Sermóes. Para uma boa reflexão sobre o tema em De filiatione dei, mas sem deixar de fazer referência a outros escritos, veja-se HAUBST, 1962, p. 29-46. Para o mesmo tema, porém, fazendo uma comparação com a filosofia echkartiana, leia-se o estudo de SCHWAETZER, 2006, p. 101-121.
} 
quando o nosso amor amante não arrasta conosco o nosso amor amável, o nexo não é suficientemente forte para que haja reciprocidade, pois amamos, mas não somos amados; ao contrário, quando a reciprocidade acontece ou quando o amante se funde com o amado num nexo de uniáo estreito e forte, realiza-se o amor perfeito, que assim não poderia ser sem o amante, o amável e o nexo, quer dizer, sem essa estrutura trina que é, ao mesmo tempo, una. Dessa maneira, encerrar o capítulo com o nexo - que pela sua forma de união pode receber o nome de filiação - significa chamar a atenção para a importância do amor, em consonância com o que é afirmado no capítulo que se segue: "Por isso, todas as coisas têm no teu conceito amável a causa ou a razão de ser. E não há causa diferente de todas as coisas a não ser que assim te agrade. E nada agrada ao amante, como amante, senáo o amável" (NICOLAU DE CUSA, 2000, p. 207) ${ }^{37}$.

Para concluir nossa incursão no De visione dei, retomemos os termos empregados para nomear a Trindade ou a estrutura trinitária que aqui se apresenta, apenas para termos uma visão de conjunto, como fizemos com o De coniecturis, abordado anteriormente. Assim, temos:

\begin{tabular}{|l|c|c|c|c|c|}
\hline \multicolumn{7}{|c|}{ De visione dei } \\
\hline \multirow{2}{*}{$\begin{array}{l}\text { Designações } \\
\text { utilizadas } \\
\text { para } \\
\text { expressar a } \\
\text { Trindade }\end{array}$} & Amor amantis & $\leftrightarrow$ & Amor amabilis & $\leftrightarrow$ & $\begin{array}{c}\text { Nexus amoris } \\
\text { amantis et } \\
\text { amabilis }\end{array}$ \\
\cline { 2 - 7 } & Infinitus amantis & $\leftrightarrow$ & Infinitus amabilis & $\leftrightarrow$ & $\begin{array}{c}\text { Nexus Infinitus } \\
\text { amantis et } \\
\text { amabilis }\end{array}$ \\
\cline { 2 - 7 } & Intellectus & $\leftrightarrow$ & Intellectus Intelligibilis & $\leftrightarrow$ & Utriusque nexus \\
\hline
\end{tabular}

DIAGRAMA 2

Percebemos que o amor, aos poucos, vai tornando-se mais explícito como designação da Trindade. Se, em De docta ignorantia, ele só aparece explicitamente no terceiro elemento da Trindade (Spiritus Sanctus sive Amor), em De coniecturis, já se encontra nas três regiōes (baixa, média e suprema),

\footnotetext{
37 "Omnia igitur in conceptu tuo amabili causam seu rationem habent essendi, neque est alia rerum omnium causa, nisi quia sic tibi placet. Nihil placet amanti ut amanti nisi amabile”. De visione dei, h VI, Cap. XIX, 83: 11-13.
} 
tendo como representantes, respectivamente, os sentidos, a razão e o intelecto, aparecendo, ainda, como terceiro elemento da luz-unitrina (lumen amoris). Em De visione dei, como pudemos notar, apesar de também aparecer unitas e intellectus para designar a Trindade, aparece, explícita e frequentemente, amor, não somente para o terceiro elemento, como ocorreu em De docta ignorantia e em De coniecturis, mas também para os três componentes da Trindade, e isso faz dela o próprio amor ou faz deste a própria Trindade, de forma que não podemos conceber a Trindade sem amor e, igualmente, conceber um amor que não seja trino. Se o peso da argumentação recai, em De visione dei, sobre o amor, significa sustentar que uma nova dinâmica é impressa às relaçóes do homem com Deus e, por extensão, com os outros homens: a dinâmica do ato de amar.

O De visione dei, mais do que qualquer outro, incita-nos a ultrapassar a relação homem-Deus ali apresentada e nos faz pensar, a partir daquela, na nossa relação com o outro. Por exemplo, se nós estendemos o nosso amor amante para outro ser diferente de nós, contudo, não nos tornamos amáveis para aquele ser, náo quer significar que nós devamos "recolher" o nosso amor ou mesmo odiar aquele que não nos ama. Pelo contrário, se nós nos reconhecemos como a contração do amor amante absoluto, não podemos odiar ninguém. Todavia, escolher ou não Deus como guia e, por isso, imitar ou não a nobreza do seu amor, que ama cada uma das suas criaturas independentemente de ser amado por elas, está no uso que fazemos da liberdade que nos foi outorgada. De toda forma, a única maneira de tornarmo-nos amáveis para o outro é, primeiramente, amando-nos, pois, como ressalta Nicolau de Cusa, à medida que vemos que nos amamos, vemo-nos como amáveis e, depois, amando o outro, já que reitera o nosso místico: o ato de amar une o amante e o amável no amor (quemadmodum amare unit amantem et amabile in amore). Logo, se o outro não nos ama, não é não o amando que podemos nos tornar amáveis para ele. Assim, o ato de amar é mostrado tanto como uma imitação do amor divino, quanto como um constante exercício do autoconhecimento humano e daquilo que queremos na nossa relação com o outro que é diferente de nós, posto que cada ser é único e irrepetível, mas também semelhante, já que é, igualmente, a unidade contraída do amor amante, do amor amável e do nexo de ambos. 


\section{CONSIDERAÇÓES FINAIS}

Do exposto, podemos afirmar que a Trindade é uma das muitas expressóes do amor, em Nicolau de Cusa, seja quando o termo aparece na "terceira" pessoa, em De docta ignorantia (e a que aqui só nos referimos), seja quando aparece sob o signo da luz, em De coniecturis, seja ainda quando une tấo fortemente os "três" elementos da Trindade numa unidade necessária, como ocorre em De visione dei. Embora o termo amor não seja o único a designar as três pessoas da Trindade, ao longo dos textos abordados, podemos perceber que o sentido do amor, mesmo quando náo aflora à superfície da reflexão sobre a Trindade, é um sentido importantíssimo para a exposição de tal temática. Afinal, implícita ou explicitamente, o amor é não somente o elo entre as duas primeiras pessoas da Trindade, mas também o nexo mais estreito e mais forte que pode haver entre aqueles dois elementos e, por extensão, entre dois seres humanos. Logo, o amor une, não somente o Filho ao Pai ou o homem a Deus, mas, igualmente, une o homem aos outros homens, fazendo-nos pensar sobre a alteridade ou sobre a multiplicidade, a partir do coração mesmo da unidade divina, que é, ao mesmo tempo, trina e una, ou seja, amante, amável e nexo e/ou amor absoluto sumamente desejável.

MARINHO, Maria Simone Nogueira. Reflections on the Trinity as expression of love in Nicholas of Cusa. Trans/Form/Ação, Marília, v. 35, p. 119-140, 2012. Edição Especial.

\footnotetext{
ABSTRACT: We seek in this paper to present the Nicholas of Cusa's reflexion on the Trinity in two of his works: De coniecturis and De visione dei. In these two books the Trinity receives several different designations from those which appear in biblical citations or, as he affirms, different designations from those used by our doctors. In this regard, our objective is to show also that the expressions of the Trinity can be read as the expressions of the Love in the thought of the German philosopher.
}

KEYWORDS: Trinity. Love. Nicholas of Cusa.

\section{REFERÊNCIAS}

\section{FONTES PRIMÁRIAS}

NICOLAI DE CUSA. Opera Omnia, iussu et auctoritate Academiae Litterarum Heidelbergensis, ad codicum fidem edita. Felicis Meiner.

Vol. I - De docta ignorantia, ediderunt E. Hoffmann et R. Klibansky, Lipsiae, 1932. 
Vol. III - De coniecturis, edidit Josephus Koch et Carolus Bormann, Hamburgi, 1972.

Vol. V - Idiota de sapientia, de mente, de staticis experimentis, ediderunt Renata Steiger et Ludovici Baur, Hamburgi, 1983.

Vol. VI - De visione dei, edidit A. D. Riemann, Hamburgi, 2000.

NICOLAU DE CUSA. A visão de Deus. Trad. e notas de J. M. André. Lisboa: Fundação Calouste Gulbenkian, 1988.

NICOLAU DE CUSA. A douta ignorância. Trad., int. e notas de J. M. André. Lisboa: Fundação Calouste Gulbenkian, 2003.

\section{FONTES SECUNDÁRIAS}

ANDRÉ, João Maria. Introdução à tradução de A visão de Deus. Lisboa: Fundação Calouste Gulbenkian, 1988.

BEIERWALTES, Werner. Identität und Differenz. Zum Prinzip cusanischen Denkens. Opladen: Westdeutscher, 1977.

FLASCH, Kurt. Nicolás de Cusa. Trad. C. Ruiz-Garrido. Spain: Herder, 2003.

HAUBST, Rudolf. Die erkenntnistheoretische und mystische Bedeutung der „Mauer der Koinzidenz". Mitteilungen und Forschungsbeiträge der Cusanus-Gesellschaft (18), 1989, p. 167-195.

. Nikolaus von Kues ueber die Gotteskindschaft. Nicolò da Cusa, Relazioni tenute al convegno interuniversitario di Bressanone nel 1960. Firenze: G. C. Sansoni, 1962, p. $29-46$.

KOCH, Josef. Nikolaus von Kues und Meister Eckhart - Randbemerkungen zu zwei in der Schrift De coniecturis gegebenen Problem. Mitteilungen und Forschungsbeiträge der Cusanus-Gesellschaft (4), 1964, p. 164-173.

ROMANO, Marino. La manifestazione della Trinità nel De visione dei di Cusano: tracce di Lullo letterali e non. Ramon Llull und Nikolaus von Kues: eine Begegnung im Zeichen der Toleranz. Turnhout-Belgium: Brepols, 2005, p. 155-174.

SCHWAETZER, Harald. L'importance d'Eckhart dans la genèse du concept cuséen de filiatio Dei. La naissance de Dieu dans l'âme chez Eckhart et Nicolas de Cues. Paris: CERF, 2006, p. $101-121$. 